\title{
CORRESPONDENCE
}

\author{
Deaths from injury \\ J Wardrope, FRCS ........................... 1668 \\ Vertebral osteomyelitis in the elderly \\ P Sell, FRCS; A J Richards, FRCP; G Bentley, \\ FRCS; G G Hartnell, FRCR ..................... 1668 \\ Breast cancer screening \\ J B Witcombe, FRCR; J P Sloane, MRCPATH, \\ and Rosemary R Millis, FRCPATH ............. 1669 \\ Myocardial infarction \\ M F Ryan, MB; D P Lipkin, MRCP, and C J \\ Reid, MRCP ................................ 1669 \\ Cervical cytology screening \\ A Smith, FFCM; W M Peters, MRCPATh, and \\ J B Kershaw, MRCPATH ...................... 1670 \\ Graves' disease \\ A P Weetman, MRCP; R L Kennedy, MRCP, \\ and T H Jones, MRCP ....................... 1670 \\ Gas gangrene \\ G E Bignardi; C R Kirk, MRCP ................ 1671 \\ Blood glucose test strips
}

P Kopelman, MRCP, and others .............. 1671
Learning from the Americans

PL Jenkins, MRCPSYCH ...

Psychiatric illness among British

Afro-Caribbeans

R Littlewood, MRCPSYCH, and M Lipsedge,

FRCPSYCH ............................... 167

Medical research

G Bevan ....

Inhaling heroin during pregnancy

C S Thomas, MRCPSYCH, and Madeline

Osborn, MRCPSYCH ...........................

Plastic material from syringes causing death

C M Backhouse, FRCS....................... 1672

Iron chelating drugs

G J Kontoghiorghes, PHD...

Outpatients

M Doublet-Stewart, DRCOG ................... 1673

Care of physically handicapped young adults

P F Ellis, MRCGP, and A O Frank, MRCP....... 1673
Diagnosing Marfan's syndrome

Anne H Child, MD.......................... 1673

Vocational training in general practice

Marie Campkin, MRCGP, and others........... 1674

Breast milk and HIV infection

R A F Bell, FRCP, and H Marcovitch, MRCP.... 1674

Disciplining doctors

Wendy Savage, FRCOG, and others ........... 1674

Allocating resources

B Essex

Points Radiation and children (H M Lee and others; D W Sarll); Walking sticks (R L Kirby and $\mathrm{P}$ J Potter); Körner, nomenclature, and SNOMED (J P Walsworth-Bell); Eye injuries caused by elasticated straps (J P Diamond); Early detection of visual defects in infancy (P A Gardiner); Meningococcal septicaemia and meningitis (P E Slater); Alcohol and mortality (Robyn N Norton and Marsha Y Morgan); Divided we fall (B E Eyes) .......... 1675

All letters must be typed with double spacing and signed by all authors.

- No letter should be more than 400 words.

- For letters on scientific subjects we normally reserve our correspondence columns for those relating to issues discussed recently (within six weeks) in the BMF.

We do not routinely acknowledge letters. Please send a stamped addressed envelope if you would like an acknowledgment.

- Because we receive many more letters than we can publish we may shorten those we do print, particularly when we receive several on the same subject.

\section{Deaths from injury}

SIR,-I congratulate Mr I D Anderson and his colleagues for their excellent review of deaths from trauma ( 7 May, p 1305). I have recently completed a study of 104 deaths from trauma in the Sheffield area, and many of my results are similar. Fifty patients received some form of resuscitation in hospital. These deaths were analysed with the TRISS (trauma score, injury severity score) method, which compares injured patients according to their state on arrival in hospital and the severity of the injury.' With these values a figure indicating the probability of survival can be obtained (by using data on survival from the major trauma outcome study from hundreds of hospitals in the United States).

With this method 16 deaths occurred in patients who were identified as having a high probability of survival. The causes of death in these patients were, however, pulmonary embolus (five patients), myocardial infarct (two), bronchopneumonia (two), severe head injury (four), and complications of tetraplegia (three). Ten of these patients were over 70 . Although these deaths were unexpected, do not think that this would equate with "preventable." Uncontrolled or undiagnosed bleeding was the cause of death in 12 other patients, but after comparison with data from the major trauma outcome study only three of them had more than a $25 \%$ chance of survival.

As a solution to the problem $\mathrm{Mr}$ Anderson and others mention establishing trauma centres in this country along the lines of those in the United States. In a recent visit to such centres I was impressed by the organisation and the results they could achieve in trauma care. It is not solely designating a hospital a trauma centre that improves the treatment of severely injured patients, however, but the development of a trauma care system. This includes better prehospital care and communications, of ten by using specialised trauma nurses and transport by helicopter; different levels of trauma centre with staff who have received basic training in evaluating and resuscitating seriously injured patients; and early fast and easy transport if specialist services are needed.

Each link in this chain of care is vital, and I believe that the basic structure of such a system already exists in this country with its district general hospitals (level two trauma centres) and the larger hospitals with regional specialties such as

\section{Vertebral osteomyelitis in the elderly}

SIR,-Dr D Thompson and others (7 May, p 1309) emphasise that the differential diagnosis of back pain covers a wide range of diseases and point out that it is all too easy to dismiss back pain in the elderly as being the result of degenerative processes.

A review of the past 51 Lessons of the Week in the $B M F$ identified 14 orthopaedic topics, of which four dealt exclusively with the misdiagnosis of spinal disease.

In only three of the 14 articles were the major authors orthopaedic surgeons. Most were reported by specialists in medicine and geriatric medicine.

I do not mean to denigrate the diagnostic skills of my medical colleagues, but when a quarter of the cases reported in Lessons of the Week cover neurosurgery, cardiothoracic surgery, and burns units (level one trauma centres). Adequate training, the presence of resident senior registrar staff, easier transfer of patients, and, above all, a commitment to care for such patients (who tend to arrive at three o'clock in the morning) should be the first goals to achieve to improve our management of trauma.

J WARDROPE

Accident and Emergency Department,

Northern General Hospital,

Sheffield S5 7AU

1 Boyd CR, Tolson MA, Copes WS. Evaluating trauma care: the TRISS method. F Trauma 1987;27:370-8.

orthopaedic topics it suggests that a greater proportion of time is required in orthopaedic training for undergraduate or early postgraduate students. This may have implications for the future provision of orthopaedic care in resolving some of the junior staffing problems ${ }^{1}$ and improving the yield of outpatient referrals.

Philip Sell

Sutton Coldfield,

West Midlands B72 IRQ

Woodyard J. The elusive orthopaedic SHO. Br Med f 1987;294:

SIR,-I work on the south coast, where there is a high proportion of elderly patients, and have 